\title{
Origins of nature tourism in imperial China
}

\author{
Libo Yan
}

\begin{abstract}
Purpose - The purpose of this paper is to apply what can be learned from the emergence of nature tourism to understand some current and future trends of tourism.

Design/methodology/approach - This study adopted the evolutionary paradigm for investigation. Findings - The emergence of nature tourism in early medieval China can be attributed to four major factors, including transformation of value orientations, seeking longevity, interest in suburbs and population migration. Research limitations/implications - Historical studies help understand the current and future trends. When the contributing factors for nature tourism are linked to the contemporary world, it can be found that these factors are still playing a part in shaping tourism trends or patterns in their original or alternative forms. These trends or patterns are worthy of scholarly investigations.

Originality/value - This paper offers a comprehensive understanding of the origins of nature tourism.
\end{abstract}

Keywords Early medieval China, Landscape appreciation, Population migration, Seeking longevity, Suburban excursions, Value transformation

Paper type Research paper

\section{Introduction}

The origins of tourism have been a fascinating area for investigation. According to Cohen (1972, as cited in Stronza, 2001), such investigation should pay attention to the specific forms of tourism as different forms of tourism might have different origins. It is thus necessary to examine the social, political and environmental factors that caused the emergence of certain types of tourism (Dann, 1981, as cited in Stronza, 2001). In the broad sense, tourism can be classified into two types, cultural tourism and nature tourism. The origins of cultural tourism have been traced to pilgrimage in the medieval world (Theilmann, 1987), or to the ancient world (Foertmeyer, 1989; Stumpf, 2003). By contrast, the origins of nature tourism received less scholarly attentions. Nature tourism refers to the contemplation of landscape scenery, or flora and fauna; the focus is nature itself, namely, its attractiveness and individual experiences (Baric et al., 2016). Meyer-Arendt (2004) attempted to explain the reasons why human are attracted to the natural environment and attributed the origins of nature tourism to traditions such as Romanticism, nature in religion and the Spring and seaside traditions. Such views neglect the leisure pursuits of literati in early medieval China, which saw the emergence of nature tourism for reasons different from those of the western world (Yan and McKercher, 2013). Investigation of the complex reasons helps understand why nature tourism emerged in China in that period. A considerable number of historical evidences showcased this milestone development in tourism history. Drawing on the evolutionary paradigm (Mannermaa, 1991; Yeoman and McmahonBeattie, 2017), this study aims to identify the critical innovations and movements in the evolution of nature tourism. The evolutionary paradigm helps the researcher to determine the major issues relevant to the observed phenomenon and offers a quick way for communicating research ideas (Bresson, 1987).

\section{The transformation of value orientations}

The Six Dynasties period (AD 220-589) saw the decline of Confucianism which regarded serving the court as the ultimate goal for the literati class (Jing and Kong, 2006). With the value orientation,
Libo Yan is based at the Faculty of Hospitality and Tourism Management, Macau University of Science and Technology, Macau, China.
Received 25 April 2018 Revised 25 June 2018 Accepted 25 June 2018

(c) Libo Yan. Published in Journal of Tourism Futures. Published by Emerald Publishing Limited. This article is published under the Creative Commons Attribution (CC BY 4.0) licence. Anyone may reproduce, distribute, translate and create derivative works of this article (for both commercial and noncommercial purposes), subject to full attribution to the original publication and authors. The full terms of this licence may be seen at http://creativecommons.org/ licences/by/4.0/legalcode 
the literati in Han Dynasty (206 BC-AD 220) were inclined to hold a positive attitude toward politics and thus extensively participated in governance of the large empire. In most time of the Han period, the emphasis of morality and social responsibility overshadowed the pursuits in individual life. The story was changed in the subsequent centuries. Political deteriorations starting from Later Han (AD 25-220) made the literati class frustrated in political engagement.

Continuous deterioration of the political environment in Six Dynasties largely weakened the literati class's interest in politics. The Wei-Jin (AD 220-420) literati began to withdraw extensively from the public domain to the individual world (Fang, 1974). Since serving the court had lost its value, the intellectual society faced a fundamental question, namely what the meaning of life was. Seeking answers to the question was accompanied by the decline of Confucianism as well as the simultaneous rise of Taoism, which brought about a significant transformation in value orientations, from devotion to hedonism (Jing and Kong, 2006).

With concerns transferred from society to individuals, the intellectual society had to reconstruct the meaning of life and give new meanings to life. The early Taoism thoughts offered theoretical support to this construction process. Master Lao's (sixth century BC) view of Tao (The way of nature) and Master Zhuang's (fourth century BC) thought of keeping spiritual freedom by disengagement in politics underlay the seeking of life meanings (Giles, 1889). His discourses on human nature plus the destructive criticism of Confucianism paved the way for the later Chinese intellectuals to seek an alternative way of life (Giles, 1889).

The Taoist classic "Lieh-tzu" was compiled in the fourth century BC, and this book described the early efforts in quest for meaning of life (Graham, 1990). The book advocates hedonism, considering that life was short and full of misfortunes. To encourage the enjoyment of life, the book emphasized that people should not be restrained by the tenets of Confucianism on fame, truth and responsibility. The book claimed that what makes sense of life is reality rather than fame which is essentially illusive. What matters is the individual and realistic experience of a happy life, rather than the etiquettes, moralities and social responsibilities emphasized by Confucianism. The Wei-Jin literati's acceptance of hedonism showed that literati's value orientation moved from altruism to individualism.

The Taoist teachings in "Chuang-tzu" and "Lieh-tzu" catered for the philosophical and psychological needs of the Wei-Jin literati. With value orientation in social life changing from devotion to hedonism, the literati life took on a new look as shown in literati's aesthetic and pleasure pursuits (Mather, 2002). The Wei-Jin literati sought pleasure in daily life, including making excursions to appreciate landscape, composing poems, listening to fine music and appreciating fine arts. With this inclination, most aspects of literati' social life tended to be artistic and graceful, and achieved a sense of aesthetics.

\section{Seeking immortality and gathering herb in mountains}

The social conditions of Six Dynasties turned out to have been appropriate for the acceptance of Taoism, both as a philosophy and as a religion. The philosophical Taoism was noted in the previous section; as for the religious Taoism, it was closely related to the practices of seeking immortality or longevity, and such practices were prevalent in Six Dynasties. Regarding mountains as dwellings of immortals was related to the aspiration for eternal life. The ancient Chinese appeared to have little doubt on the belief that the immortals lived on mountains. In the first century AD, dictionaries defined the term, xian, as "to live to an old age without dying, and move into mountains" (see Shiming and Shuowen Jiezl). Having attained ideas of dwellings of the immortals, the ancient Chinese began their long process of quest for immortality. Immortality seeking dates back to the fourth century $\mathrm{BC}$, and the antiquity saw the tide of immortality seeking represented by kings and emperors (Wang and Yu, 2005). Typical among those immortality seekers were the First Emperor (Qinshihuang) and Emperor Wu of Han (Hanwudl), both sparing no efforts in attempts of turning their dreams of eternal life into reality. Besides asking Taoist adepts to hunt for elixirs, the two emperors traveled frequently in the vast land of their empire, made sacrifices to famous mountains and ascended mountains beside the sea, dreaming about attaining immortality. Unfortunately, all of their efforts were in vain. 
In later eras, while some people followed previous examples and continued immortality seeking on mountains or islands, others began to explore alternative ways for becoming immortal. The latter thought that immortality should be achieved through self-cultivation. As an outstanding philosopher or representative literati in his time, Ji Kang (224-263) did not believe in the existence of immortals, but he held the belief that human life could be extended by taking herbs or other ways of self-cultivation (Fang, 1974). In a letter to his friend Shan Tao, Ji Kang wrote:

I have studied in the esoteric lore of the Taoist masters, where a man's life can be indefinitely prolonged through eating herbs, and I firmly believe this to be so. To wander among the hills and streams, observing fish and birds, is what gives my heart great pleasure (tr. Minford and Lau, 2000, p. 466).

The herbs taken to extend life should be gathered by the person himself who expected a long lifespan, and thus it was necessary to go to the mountains. Ge Hong's (283-363) "The Inner Chapters of Baopuzi" (Ware, 1966) systematically described the approaches for self-cultivation. Ge suggested that mountains were ideal sites for self-cultivation since the secluded mountains helped immortality seekers to firm their wills and be unaffected by the mundane world. The famous mountains had their own gods who might assist the preparation of the divine elixir. On the famous mountains, earth immortals might be encountered and magic fungi and herbs grew there, both of which were helpful for the making of divine elixirs.

Since Ge Hong's time, to meet the increasing need of ideal sites for self-cultivation more and more mountains had been added to the original list of sites. Till the early seventh century, the number of optimal sites or "Caverns of heaven and place of blessing" had been increased to 118 (Zhou, 1996). Most of the optimal sites centralized in regions close to the metropolis Jiankang, the political center in Six Dynasties. Having regarded famous mountains as abodes of immortals as well as optimal sites for the divine process, many Taoists went to famous mountains to seek immortality. Through the exemplification effect of early Taoists' behaviors, famous mountains received extensive attention from people living in the mundane world. The Taoist laymen or common literati then imitated Taoists' behaviors by going to famous mountains for herb gathering and immortality seeking. The behavior mode had a significant impact on the evolution of landscape appreciation.

Herb gathering was as an important activity not only for early Taoists but also for their successors in Six Dynasties. Most of the aristocratic families of that period believed in Celestial Master Taoism, and mastered herbalism was a cornerstone of religious Taoism (Chen, 1992). The interest in herbs drove aristocratic literati to mountains, which had a linkage to the appreciation of mountains sceneries. Literati going to mountains would take the opportunity to look around and paid attention to the scenes. Wang (1986) analyzed the association between the two activities, gathering herbs and viewing landscape, and suggested that there was a natural linkage between them:

The initial purposes of going to the mountains were seeking immortality or gathering then taking herb, in the hope of breaking the temporal and spatial thresholds and enjoying the freedom like a divinity. However, whether for immortality-seeking or for herb gathering, the literati needed to gaze to the east or the west, and look forward and backward. In doing so, they caught sight of the famous mountains, which was described as the abodes of immortals in legends. [...] The mountain sceneries and the fairyland, then, naturally became the objects appreciated by poets (p. 88).

The literati's herb gathering was different from that of a commoner, which might be explained by their different identities. The commoner needed to make a living by gathering herbs, and thus their major concern was how to collect more desirable herbs. However, the literati had no such a concern since they regarded herb gathering as a way of satisfying their spiritual needs rather than the material ones. Therefore, going to the famous mountains to gather herbs was more a leisure activity than a labor for them. In mountains, their exploration would not be bound to gathering herbs, and they would pay attention to the diverse natural objects. In this sense, literati's exploration of the mountains for herb gathering objectively facilitated the appreciation of sceneries, which was explained by Wang (1986) as below:

It is time-consuming to go to the mountains for immortality seeking and herb gathering. Once in the famous mountains and deep forests, the literati were secluded from the occurrences in human life and far from the mundane world [...] Forsaking the worldly affairs, the literati might have been indifferent to 
fame or gain in the mundane world and immersed in the tranquil environment. Such relatively long periods of contact with nature would undoubtedly enhance the aesthetic appreciation of mountains and streams (pp. 92-3).

The desire for wandering in famous mountains with the excuse of herb gathering was common among the literati class since the mid-third century. Once in the mountains, they would pay more attention to scenery than to herbs.

Taoist literati could not claim monopoly of the behavior of collecting herbs and visiting famous mountains, considering that Buddhist literati also engaged in such activities. In a preface to poetry, Zhi Dun (314-366), a celebrated monk of Eastern Jin, showed an interest similar to that of Taoist literati discussed previously:

I enjoy the calmness of the wild area, adding the desire to gather herb, so I went alone [to Mount Tu in Wu Prefecture] [...] While climbing the mountain and collecting herbs I took pleasure from the appreciation of rocks and streams (Lu, 1983, p. 1079, tr. author).

The above discussions show that with the participation of the affluent, leisurely literati, herb gathering slowly evolved into an outdoor recreation that had a certain degree of relationship with landscape appreciation. Wandering on mountains with the excuse of gathering herb offered cherished opportunities for landscape appreciation, but such opportunities were uncommon for the literati class. The reason, besides the spatial factor, lies in the temporal constraint, namely, literati officials had insufficient time for traveling to and wandering in famous mountains. The Jin literati solved this problem by using the suburban hills as an alternative. In doing so, literati overcame the spatial and temporal constraints for viewing sceneries. They appeared to be satisfied with the suburban settings as a substitute for their desirable destinations, namely, famous mountains, as Emperor Jianwen, Sima Yu (320-372) stated on entering the Flower Grove Park: “The spot which suits the mind isn’t necessarily far away” (tr. Mather, 2002, p. 63).

\section{The rising interest in excursion to suburbs}

The term "suburb" refers to a historical, rather than recent, phenomenon (Harris and Larkham, 1999). Six Dynasties saw the emergence of many cities in the south of China due to developed agriculture and commodity economy (Jian and Ge, 1996). Accordingly, the conception of suburb in Six Dynasties should not be understood as wildness (Yan, 2015); instead, suburbs at that time consisted of natural existences such as riverside, lakeside and hilltop on the outskirts of cities, as well as human construction such as landscape gardens, villas, estates and pavilions (Zhou, 1999). The rural scene was also a part of the suburb but to a large extent neglected by the literati in the Wei-Jin period (Kang, 2006).

Starting from the third century, the Chinese literati began to make excursions to the suburbs for various reasons, such as composing poems, philosophical debates, listening to music, drinking wine and enjoying desirable outdoor settings (Yan, 2010). Before succeeded the throne of Wei Kingdom, Cao Pi, together with other literati, enjoyed outings to a suburban garden as he wrote: "During those old days we would go outing together. [...] We passed around goblets, listened to music; when our ears became hot from drinking, we would look up and write poetry" (tr. Wu, 2008, p. 40).

The literati in Western Jin also enjoyed musical performance in the natural settings as typically illustrated by the case of the Golden Valley gathering. The party host Shi Chong (249-300) depicted:

Day and night we roamed about and feasted, each time moving to a different place, sometimes climbing to a height and looking down, sometimes sitting by the water's edge. At times seven- or twenty-five-stringed zithers, mouth organs, and bamboo zithers accompanied us in the carriages, and were played in concert along the road. When we stopped, I had each person perform in turn with the orchestra (tr. Mather, 2002, pp. 284-85).

In such outings, music performance and appreciation attracted much attention of participants, thus overshadowing the appreciation of sceneries.

The outing behavior predominated by music appreciation was criticized by Zuo Si (c. 252-c. 306), who proposed that when in the natural environment, one should pay attention to the beauty of 
sceneries, without the interruption of music: "Why must one have strings and flutes?/ When mountains and streams give forth their pure notes" (tr. Holzman, 1996, p. 118). Zuo Si felt that in the wild area the beautiful scenery was an ideal substitute for the mundane music from which literati usually took pleasure in their daily life. Zuo Si's poem disclosed the independent value of landscape, advocating literati to appreciate scenery for its intrinsic beauty rather than as settings for banquets or musical performances. He suggested the literati who patronized mountains concentrate on the intrinsic beauty of nature, not allowing the mundane music to hold back their communication with nature. Zuo Si's idea could be regarded as a milestone in the evolution of landscape consciousness.

The innovative idea of Zuo Si had significant influence on later literati as illustrated by a later, grand gathering organized by Wang Xizhi (303-361) at Orchid Pavilion in AD 353 (see Yan, 2015). The participants, with the influence of Zuo Si, seated themselves along a swirling, splashing and curving stream, playing a game of floating goblets and composing poems. At that occasion they did not have music as in daily life, but the pleasure they felt was never inferior to that of their Golden Valley counterparts who were accompanied by musical instruments all the way. The participants of the Orchid Pavilion gathering were supporters of Zuo Si's idea of removing music from excursions and allocating one's attention to the nature per se. The party host, Wang Xizhi, appeared to have been mostly influenced by Zuo Si, and thus no music performance was arranged in the gathering. He mentioned: "Though we had none of the magnificent sounds of strings and flutes, a cup of wine and then a poem were enough to stir our innermost feelings" (tr. in Lavallee, 2004, p. 248). Other participants showed a positive attitude toward the arrangement and spontaneously depicted the music-like natural sounds they enjoyed as summarized in Table I.

To a large extent, the Orchid Pavilion poets agreed that the pure notes from mountains and streams were an ideal substitute for musical sounds. Apart from audio landscape, the poets allocated many lines to describe the sceneries surrounding the Orchid Pavilion (see Lavallee and Yan, 2010). The acceptance of Zuo Si's idea largely explains the Orchid Pavilion poets' appreciation of the visual and audio landscape at Orchid Pavilion.

Having a desire for wandering in famous mountains but no immediate access, the literati class brought the mountains to them by using suburban hills as a substitute. As the Orchid Pavilion poet Xi Tan wrote: "Sitting straight up rouses distant thoughts; with light chatter we roam the suburbs" (tr. Lavallee, 2004, p. 254). The suburban hills might not be as sublime as the famous mountains, but this did not weaken literati's interest in excursions to the suburbs. After all, suburban hills were easy to reach by ox cart or boat, or by riding a horse.

As a compromise of the desire for far-off journeys to famous mountains, the suburban excursions offered a convenient opportunity for proximity to the natural world. In the outskirts of cities like Ye of Wei, Luoyang of Western Jin, Jiankang and Kuaiji of Eastern Jin, a collective interest in landscape was cultivated (Yan, 2010). The suburban settings were significant for the evolution of landscape appreciation. It is in the meaningful suburbs that the early medieval literati cultivated a shared interest in landscape. However, the aesthetic experiences they attained in the suburbs appeared to be superficial, and the literati tended to be satisfied with an overview of landscape and neglected the aesthetic details (Lavallee, 2004). The literati class needed a broader space to enrich their landscape experiences.

\section{Table I Orchid Pavillion poets echoing Zuo Si}

Poets Depiction of natural sounds

Wang Xizhi

Xie Wan

Xu Fengzhi

Sun Tong
The profound spring possesses pure sound In the valley stream there is a pure echo Pure sounds imitate the strings and flutes The ten thousand sounds blow among the linked peaks

Source: Yan (2010) 


\section{The migration of cultural elites from north to south}

To understand the history of Easter Jin, one should look into the mass population migration in that period (Hu, 2010). This viewpoint applies to the evolution of nature tourism in Eastern Jin. The internal rebellions plus insurgence of ethnic peoples in the northern China brought the Western Jin administration to its end in AD 316 (Chen and Wan, 1995). To leave the battlefield of northern ethnic peoples, a large number of Han people, including aristocrats and landowners in central China, migrated to the relatively peaceful south to seek a safe refuge (Chen and Wan, 1995). Actually, the migration or withdrawal had already been planned. In the beginning of the fourth century, the Jin society was in a chaotic state because of the rebellions of eight princes. The upper class lost their confidence in the restless north, and thus had already begun their preparations for the scheduled retreat. After the fall of Western Jin, the migrated upper class established the Eastern Jin court in Jiankang (present Nanjing, Jiangsu). For the first time in the history, China's cultural center was transferred from north to south.

Having crossed the Yangtze River, the aristocratic families found that the area of Jiankang had insufficient land for them to settle down, and the lower reach of the Yangtze River had already been occupied by the northern middle class who had advantages in terms of both population and military power. Furthermore, the fertile lands around the Five Lake (present Lake Tai) were controlled by the aboriginal residents, Wu people. The migrating aristocratic families crossed the Zhe River and settled down in Kuaiji (present Shaoxing, Zhejiang) (Chen and Wan, 1995) and enjoyed living there.

The settled aristocrats found that the land of Kuaiji was not only fertile enough to support their mega families but also abundant in sceneries to meet their aesthetic needs. The gazetteers of Kuaiji described that:

In the Kuaiji area there is an especially large number of famous mountains and streams, where peaks tower, lofty and precipitous, disgorging and swallowing clouds and mist; where pines and junipers, maples, and cypresses rise with mighty trunks and gaunt branches; and where lakes and pools lie mirror-like and clear (tr. Mather, 2002, p. 75).

The Kuaiji settlement saw the convergence of talents of that time. The biography of Wang Xizhi (303-361) in the official history of Jin Dynasty reads:

There are beautiful landscapes in Kuaiji and many famous men made their homes there. Xie An used to live there before he took office. Sun Chuo, Li Chong (fl.c. 330), Xu Xun and others, all of whom were among the best writers of the time, had houses built in the eastern region and were on good terms with Xizhi (tr. Frodsham, 1960, p. 87).

The convergence of best writers and artists of the time in Kuaiji made the place a cultural center of Eastern Jin (see Yan and McKercher, 2013). The aristocratic literati had been originally scattered in the vast land of north, but because of the southward migration they gathered in the same place. The convergence made the literati communication convenient as well as frequent. The spatial proximity of these literati and artists accelerated the formation of the culture of landscape appreciation. Sources of the period disclose that these literati shared similar lifestyles in terms of tending to live in retirement and being addicted to the intrinsic beauty of nature (Fang, 1974; Mather, 2002). That is what culture means, namely, the way of life for a particular group of people. The role of the locale of Kuaiji in forging a culture of landscape appreciation is similar to that of the Lake District in Cumberland for cultivating the English school of nature perception (Frodsham, 1967; Yan, 2015).

The migration brings about a vivid contrast of residential environments. Prior to the migration, the northern aristocrats lived in a geographical environment where "the sky is grey, grey, and the steppe wide, wide" with such common scenes as "over grass the wind has battered low, sheep and oxen roam" ( $\mathrm{Hu}, 2010, \mathrm{p} .607)$. After the migration, they began to live a new life in an elegant environment "where clear streams overflow, hills are shrouded in mist, brightly colored flowers appear on trees, and flocks of orioles flit across the hills, inflaming the literary sentiment on the quality suggestive of poetry and painting" (Hu, 2010, p. 607). The new environment was so appealing that the immigrated literati were deeply attracted as exemplified by the case of Wang Xizhi: "since the moment he firstly crossing the Zhe River, he had the intention of remaining there the rest of his life" (Fang, 1974, p. 2098). The abrupt change urged the immigrants to 
"learn and understand the new geographical environment" ( $\mathrm{Hu}, 2010, \mathrm{p} .606)$ and the era became an age of geographical discoveries. Sun Tong's ( fl. fourth century AD) biography says that he took a governmental position primarily for the convenience of appreciating scenery in the prefecture he administrated:

He settled in Kuaiji (Zhejiang), since by nature he was fond of hills and streams. When he sought to become magistrate of Yin Prefecture (near Ningbo), he neglected all petty duties and let his fancy free, roaming about for pleasure. There was not a famous hill or outstanding stream he had not viewed in his travels (tr. modified from Mather, 2002, p. 414).

Xu Xun's (ca. 325-ca. 352) love of nature was admired by his contemporaries:

Xu Xun was fond of wandering among mountains and streams and his physique was well suited to mountain climbing. His contemporaries used to say, "Xu not only has superb feelings; he really has the equipment for traversing the superb [i.e. mountain resorts] (tr. Mather, 2002, p. 362).

Apart from geographical discovery, traveling between Kuaiji and the capital Jiankang was a critical part of the aristocratic literati's social life (Yan and McKercher, 2013). Frequent travels became necessary since the male members of these aristocratic families needed to pursue their political careers and maintaining the social network in the capital, Jiankang. These journeys, plus the collective awareness of landscape literati cultivated in Kuaiji, further stimulated the aesthetic consciousness of Kuaiji literati. The distance between Kuaiji and Jiankang was approximately $560 \mathrm{~km}$ by water or over land (Shen, 1974). For most of the time, the literati stayed in ships, and this way of mobility was appropriate for appreciating sceneries. The traveling literati appreciated sceneries along the route, including suburban hills, waterscapes and gardens (Yan and McKercher, 2013). It was traveling back and force between the cultural and political centers that made these landscape sites accessible. In this regard, the Ming Dynasty literati Xie Zhaozhe (1567-1624) had a comment:

Mountains and rivers have to be in the right place. If they are located in remote areas, and have no accessibility, they will remain unknown to the world. By contrast, the Tiger Hill in Gusu, beside a grand mountain, appears to be nothing more than a hillock and not worthy of allusions. But it is near the regional hub of traffic, both over land and by water, therefore, it has been frequently visited and appreciated in the last millennium. So mountains could be categorized into two types, fortunate and unfortunate (Xie, 2001, tr. author).

The Tiger Hill noted in the above quotation was located between Kuaiji and Jiankang. The small hill and many others en route had received patronage since Eastern Jin, thus being "fortunate" because of the migrated aristocrats' frequent mobility between the two centers.

\section{Looking forward}

The investigation of the origins of nature tourism in ancient China has implications of understanding the current and future tends of tourism development. The four factors, transformation of value orientations, seeking immortality, interest in suburbs and migration, functioned together and contributed to the emergence of nature tourism in the third and fourth centuries in imperial China. The findings have some implications for understanding the evolution of tourism in the contemporary and future worlds.

First, transformation of value orientations can bring about new forms of tourism or leisure. The change of values contributed to landscape appreciation as a new form of leisure for early medieval Chinese literati. To a certain extent, this experience was shared by the western societies. Prior to the Romantic era, the irregular natural objects such as mountains were regarded as ugly and undesirable (Nicolson, 1997). However, "the Romantic Revolution in literature and thought in the nineteenth century [...] [and] the change in attitude towards mountains and wild lands [...] [caused] the rapid growth of the appeal of mountainous regions" (Butler, 2015, p. 19). Those activities related to mountains and wilderness emerged as new forms of tourism, which were significant and long-lasting for the nineteenth century and afterwards. Viewing mountains, climbing and walking in mountains, and then using mountains as the setting for sports can be regarded as outcomes of the changed attitude toward the natural world (Butler, 2015). 
Second, seeking longevity continues in the contemporary world, and a few destinations with long lifespan are popular in the tourism market, such as the Bama County in Guangxi, China (Huang and Xu, 2018; Liu et al., 2015). Seeking physical attractiveness facilitates cosmetic surgery tourism in Thailand, South Korea, Costa Rica (Ackerman, 2010; Enteen, 2014; Holliday et al., 2017). The social and economic impact of cosmetic surgery tourism awaits scholarly investigations.

Third, the essential reason for excursions to suburbs remains the same as in Eastern Jin, that is, lack of accessibility to distant destinations because of temporal and spatial restraints. With the policy of five-day work week extensively adopted in most countries and territories in recent decades, the suburban areas surrounding a metropolitan city have an important part to play in satisfying the recreation need of urban residents. Based on investigation of visitor flow to suburban areas, Wu and Cai (2006) proposed the concept "recreational belt around metropolis," the formation of which was attributed to demand for weekend recreation and the infrastructure development.

Fourth, seeking a better place to live is an everlasting trend. For a better climate and environment, or for quality of life, those retired population widely engaged in lifestyle migration, seasonally traveling between their origin and a given destination (Kordel, 2016). This lifestyle migration brings about the phenomenon of residential tourism characterized by the ambiguous identity of the lifestyle migrant, half tourist and half resident (Torkington, 2010). Catering for the tourism or recreation need of these residential tourists generate problem and questions for the government and business sectors.

\section{References}

Ackerman, S.L. (2010), "Plastic paradise: transforming bodies and selves in Costa Rica's cosmetic surgery tourism industry”, Medical Anthropology, Vol. 29 No. 4, pp. 403-23.

Baric, D., Anic, P. and Bedoya, A.M. (2016), "Segmenting protected area visitors by activities: a case study in Paklenica National Park, Croatia”, European Journal of Tourism Research, Vol. 13, pp. 103-21.

Bresson, C.D. (1987), "The evolutionary paradigm and the economics of technological change", Journal of Economic Issues, Vol. 21 No. 2, pp. 751-62.

Butler, R. (2015), "The evolution of tourism and tourism research", Tourism Recreation Research, Vol. 40 No. 1, pp. 16-27.

Chen, Y. (1992), Selections of Chen Yinke's papers of Historical Studies, Shanghai Classics Publishing House, Shanghai.

Chen, Y. and Wan, S. (1995), Record of Chen Yinke's Lectures on Histories of Wei, Jin, Southern and Northern Dynasties, Yun Long Press, Taipei.

Enteen, J.B. (2014), "Transitioning online: cosmetic surgery tourism in Thailand", Television \& New Media, Vol. 15 No. 3, pp. 238-49.

Fang, X.L. (Ed.) (1974), An Official History of the Jin Dynasty, Zhonghua Book Company, Beijing.

Foertmeyer, V.A. (1989), Tourism in Graeco-Roman Egypt, unpublished doctoral thesis, Princeton University, Princeton, $\mathrm{NJ}$.

Frodsham, J.D. (1960), "The origins of Chinese nature poetry”, Asia Major, Vol. 8, pp. 68-103.

Frodsham, J.D. (1967), "Landscape poetry in China and Europe”, Comparative Literature, Vol. 19 No. 3, pp. 193-215.

Giles, H.A. (1889), Chuang Tzu: Mystic, Moralist, and Social Reformer, Bernard Quaritch, London.

Graham, A.C. (1990), The Book of Lieh-tzu: A Classic of Tao, Columbia University Press, New York, NY.

Harris, R. and Larkham, P.J. (1999), "Suburban foundation, form and function", in Harris, R. and Larkham, P.J. (Eds), Changing Suburbs Foundation, Form and Function, E \& FN Spon, London, pp. 1-31.

Holliday, R., Cheung, O., Cho, J.H. and Bell, D. (2017), "Trading faces: the 'Korean look' and medical nationalism in South Korean cosmetic surgery tourism”, Asia Pacific Viewpoint, Vol. 58 No. 2, pp. 190-202. 
Holzman, D. (1996), Landscape Appreciation in Ancient and Early Medieval China: The Birth of Landscape Poetry, National Tsing Hua University, Hsinchu.

$\mathrm{Hu}, \mathrm{A}$. (2010), "The population migration and its influence in the period of the Eastern Jin, the sixteen states, and the Northern and Southern dynasties", Frontiers of History in China, Vol. 5 No. 4, pp. 576-615.

Huang, L. and Xu, H. (2018), "Therapeutic landscapes and longevity: wellness tourism in Bama”, Social Science \& Medicine, Vol. 197, pp. 24-32.

Jian, X. and Ge, Z. (1996), "Six dynasties industry and commerce and the economic development in the middle and lower yangtze plain", in Jiangsu Province Society of Six Dynasties History and Institute of History at Jiangsu Academy of Social Science (Eds), Economic Development in the Lower Yangtze Plain in Medieval China, San Qin Publishing House, Xi'an, pp. 204-21.

Jing, S. and Kong, Y. (2006), The Intellectual History of Ancient china: The Volume of the Wei, Jin, Southern and Northern Dynasties, Guangxi People's Publishing House, Nanning.

Kang, C.C. (2006), "Essays on landscape Idyllic poems of the six-dynasties", Journal of Far East University, Vol. 23 No. 2, pp. 381-88.

Kordel, S. (2016), "The production of spaces of the 'good life' - the case of lifestyle migrants in Spain", Leisure Studies, Vol. 35 No. 2, pp. 129-40.

Lavallee, T.M. (2004), "Formality and the pursuit of pleasure in early medieval Chinese banquet poetry", unpublished doctoral dissertation, Washington University, Saint Louis, MO.

Lavallee, T.M. and Yan, L. (2010), “'Galloping our minds beyond the boundaries': exploring leisure in the poetry of the Orchid Pavilion gathering”, Journal of China Tourism Research, Vol. 6 No. 2, pp. 85-103.

Liu, Y., Nie, L., Wang, F. and Nies, Z. (2015), "The impact of tourism development on local residents in Bama, Guangxi, China”, Tourism Economics, Vol. 21 No. 6, pp. 1133-48.

Lu, Q. (Ed.) (1983), The Most Complete Collection of Pre-Tang Poetry, Zhonghua Book Company, Beijing.

Mannermaa, M. (1991), "In search of an evolutionary paradigm for futures research", Futures, Vol. 23 No. 4, pp. 349-72.

Mather, R. (2002), Shih-shuo Hsin-Yu: A New Account of Tales of the World (edited by Liu I-ch'ing, with commentary by Liu Chunand translated with introduction and notes by R.B. Mather), 2nd ed., University of Michigan, Ann Arbor, Ml.

Meyer-Arendt, K. (2004), "Tourism and the natural environment", in Lew, A.A., Hall, C.M. and Willams, A.M. (Eds), A Companion to Tourism, Blackwell, Malden, MA, pp. 425-37.

Minford, J. and Lau, J.S.M. (Eds) (2000), Classical Chinese Literature, Vol. 1, Columbia University Press; The Chinese University Press, New York, NY and Hong Kong.

Nicolson, M.H. (1997), Mountain Gloom and Mountain Glory: The Development of the Aesthetics of the Infinite, University of Washington Press, Seattle, WA.

Shen, Y. (1974), Official History of Liu-Song Dynasty, Zhonghua Book Company, Beijing.

Stronza, A. (2001), "Anthropology of tourism: forging new ground for ecotourism and other alternatives", Annual Review of Anthropology, Vol. 30 No. 1, pp. 261-83.

Stumpf, J.A. (2003), "Tourism in Roman Greece ", unpublished doctoral dissertation, University of Missouri, Columbia, MO.

Theilmann, J.M. (1987), "Medieval pilgrims and the origins of tourism", The Journal of Popular Culture, Vol. 20 No. 4, pp. 93-102.

Torkington, K. (2010), “Defining lifestyle migration”, Dos Algarves, Vol. 19, pp. 99-111.

Wang, G. (1986), Studies of China's Landscape Poetry, Linkingbooks, Taipei.

Wang, Y. and Yu, H. (2005), The Culture of Wandering Immortal in Imperial China, 2nd ed., Fudan University Press, Shanghai.

Ware, J.R. (1966), Alchemy, Medicine, Religion in the China of AD 320: The Nei P'ien of Ko Hung (Pao-p'u tzu), The MIT Press, Cambridge.

Wu, B. and Cai, L.A. (2006), "Spatial modeling: suburban leisure in Shanghai", Annals of Tourism Research, Vol. 33 No. 1, pp. 179-98. 
Wu, F. (2008), Written at Imperial Command: Panegyric Poetry in Early Medieval China, State University of New York Press, Albany, NY.

Xie, Z. (2001), Wu Za Zu, Liaoning Education Publishing House, Shenyang.

Yan, L. (2010), "The contribution of early medieval China (AD 220-589) to the travel culture of landscape appreciation", unpublished doctoral dissertation, The Hong Kong Polytechnic University.

Yan, L. (2015), "What landscape meant for the early medieval Chinese gentry", Asia Pacific Journal of Tourism Research, Vol. 20 No. 11, pp. 1195-211.

Yan, L. and McKercher, B. (2013), "Travel culture in eastern Jin China (317-420 AD): the emergence of a travel culture of landscape appreciation”, Annals of Tourism Research, Vol. 43, pp. 20-36.

Yeoman, I.S. and Mcmahon-Beattie, U. (2017), "The turning points of revenue management: a brief history of future evolution”, Journal of Tourism Futures, Vol. 3 No. 1, pp. 66-72.

Zhou, W. (1996), Well-Known Mountain Resorts in China, Tsinghua University Press, Beijing.

Zhou, W. (1999), A History of Classic Gardening in Imperial China, 2nd ed., Tsinghua University press, Beijing.

\section{Corresponding author}

Libo Yan can be contacted at: Ibyan@must.edu.mo

For instructions on how to order reprints of this article, please visit our website: 